\title{
Expected Information of Users for the OTC Drugs in Japan
}

*Kiyomi Sadamoto, Yutaka Higashimata, Masaru Mizoguchi, Takahiro Yamanouchi, Noriyuki Kinoshita, and Tsuyoshi Saeki

Department of Clinical Sciences, Pharmaceutical Sciences, Toho University, Tokyo, Japan

\begin{abstract}
Background: The safety of self medication with OTC (Over the Counter) is of concern since the recent change in selling of OTC drugs in Japan. However, there have been few objectives and subjective evaluations for the safety of OTC drugs in daily use.
\end{abstract}

Method: A questionnaire about OTC drugs was composed, and distributed to users who were first informed about the purpose of the research.

Result: The most common item is instruction on the outer box, and instruction on container (bottle) is less than $20 \%$. And less than $30 \%$ of users review the package insert.

Conclusion: From this study, we recognize that information of outer box is the most common information source for all users.

\section{Back ground}

The safety of self medication with OTC (Over the Counter) is of concern since the recent change in selling of OTC drugs in Japan $[1,2]$. However, there have been few objectives and subjective evaluations for the safety of OTC drugs in daily use. With the expand of opportunity of selling OTC drugs from pharmacy to now the supermarket and convenience store, safe use is now a serious issue in Japanese society. Currently, there is no rigid standard guideline for understandable instruction and safety-warning in the package design for OTC drugs. Instruction for OTC use are commonly found on the outer package, the medication bottle itself, and in a detailed package insert. Understanding users expectations for obtaining information about OTC drugs is essential for promoting safe self-medication [3-5].

\section{Aim}

To study the needs of OTC drugs when users buy and use them, and considering the essential and important provisions of packaging.

\section{Method}

A questionnaire about OTC drugs was composed, and distributed to users who were first informed about the purpose of the research. Questions include standards of choice, reading instruction, necessary information and inconvenience of use. The data of questionnaire was analyzed with Chi-square test.

\section{Results}

1. Table1 shows number of groups divided with ages. Distribution of ages is from teenagers to 60 's.

2. Figures 1, 2 shows the criterion items for the selection of OTC drugs at the time of purchase. Figure 1 shows the distinction of sex, both male and female have criterion for efficacy and price, but female users look upon recommendation from family, acquaintance and shop staff important significantly more when compared with

\begin{tabular}{|l|l|l|l|l|}
\hline & Under 29 & 30 to 49 & 50 to 69 & Total \\
\hline Male & 38 & 45 & 42 & 125 \\
\hline Female & 31 & 27 & 23 & 81 \\
\hline Total & 69 & 72 & 65 & 206 \\
\hline
\end{tabular}

Table1: Distribution of respondents. males. Figure 2 shows criterion difference of age groups, efficacy and price are a higher priority in every generation; on the other hand dosage form and frequency of taking have less priority. Patients in these 30's and 40's have more conscious for brand name and conventional usage.

3. Figures 3,4 shows the most common item of instruction used by patients when they use OTC drugs. The most common item is instruction on the outer box, and instruction on container (bottle) is less than $20 \%$. And less than $30 \%$ of users review the package insert;

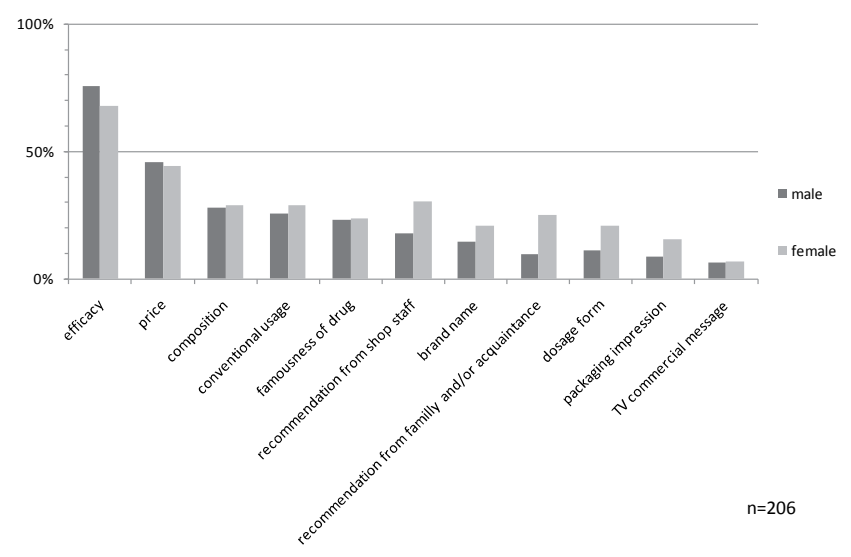

Figure1: Criterion items for choosing OTC drug at the time of purchase. (Comparison of sex).

*Corresponding author: Kiyomi Sadamoto, 2-2-1 Miyama, Funabashi, Chiba 274-8510, Japan, E-mail: sadamott@bd.mbn.or.jp

Received October 24, 2011; Accepted January 17, 2012; Published January 20 2012

Citation: Sadamoto K, Higashimata Y, Mizoguchi M, Yamanouchi T, Kinoshita $\mathrm{N}$, et al. (2012) Expected Information of Users for the OTC Drugs in Japan. Adv Pharmacoepidem Drug Safety 1:101. doi:10.4172/2167-1052.1000101

Copyright: (c) 2012 Sadamoto $\mathrm{K}$ et al. This is an open-access article distributed under the terms of the Creative Commons Attribution License, which permits unrestricted use, distribution, and reproduction in any medium, provided the original author and source are credited. 
Citation: Sadamoto K, Higashimata Y, Mizoguchi M, Yamanouchi T, Kinoshita N, et al. (2012) Expected Information of Users for the OTC Drugs in Japan. Adv Pharmacoepidem Drug Safety 1:101. doi:10.4172/2167-1052.1000101

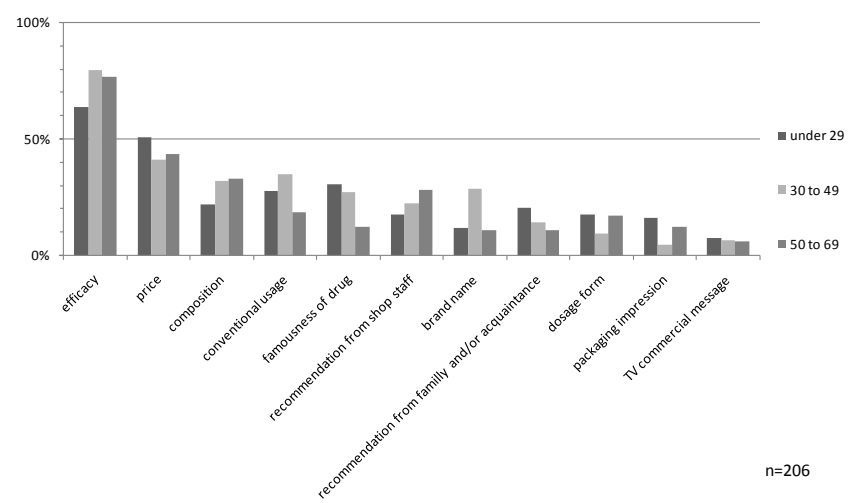

Figure 2: Criterion items for choosing OTC drug at the time of purchase. (Comparison of age).

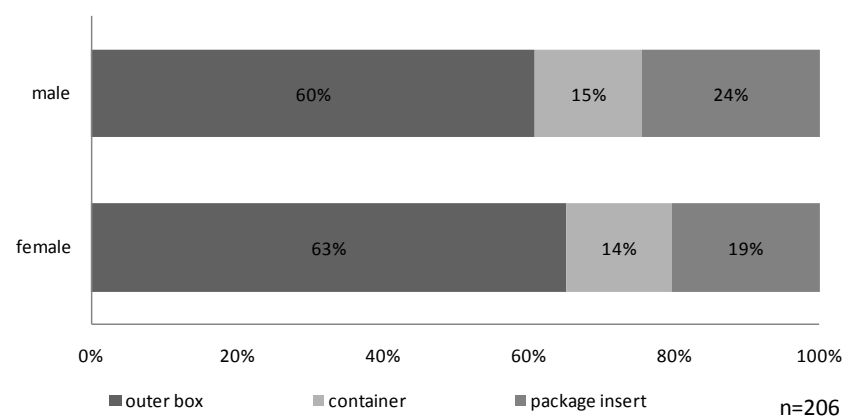

Figure 3: Location the most ensured instruction printed at the time of using OTC drugs. (Comparison of sex).

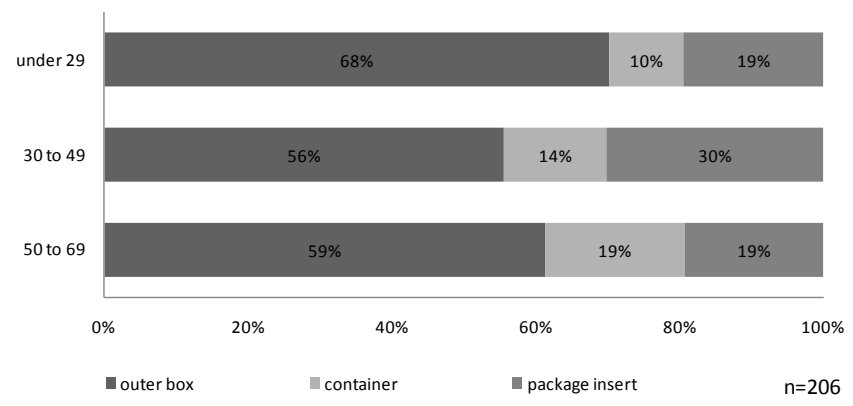

Figure 4: Location the most ensured instruction printed at the time of using OTC drugs. (Comparison of age).

there is no difference with age groups and distinction of sex in this tendency.

4. Figures 5, 6 shows information which users confirm when they take OTC drugs. Dosage and administration is the most common item of review, $72 \%$ to $90 \%$ of all users confirm it both with the analysis of distinction of sex and age groups respectively. Attention to cautions and warning are confirmed by $52 \%$ to $70 \%$ of all users with the analysis of distinction of sex and age groups respectively. Less than $32 \%$ of all users confirm expiration date.

5. Figures 7,8 shows inconveniences and problems when users take OTC drugs. From the analysis of distinction of sex, the fine print of the instruction is rated most inconvenience in both male; $32 \%$ and female; $33 \%$. And difficulty of finding the most important

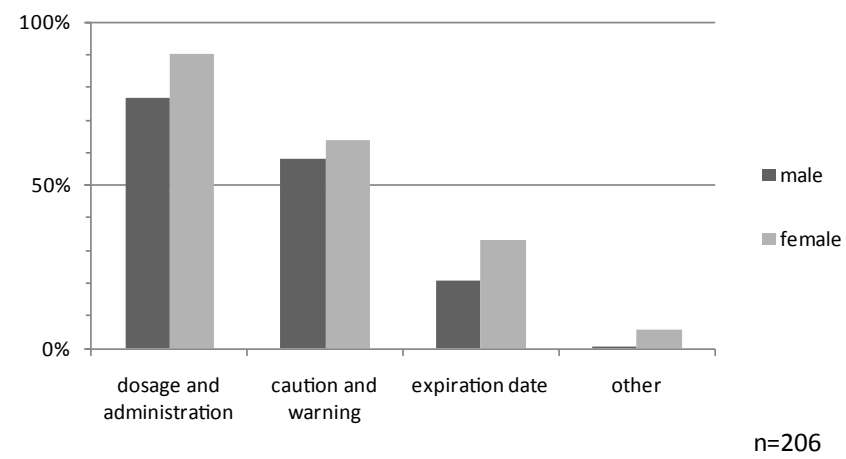

Figure 5: Ensured items for using OTC drugs. (Comparison of sex).

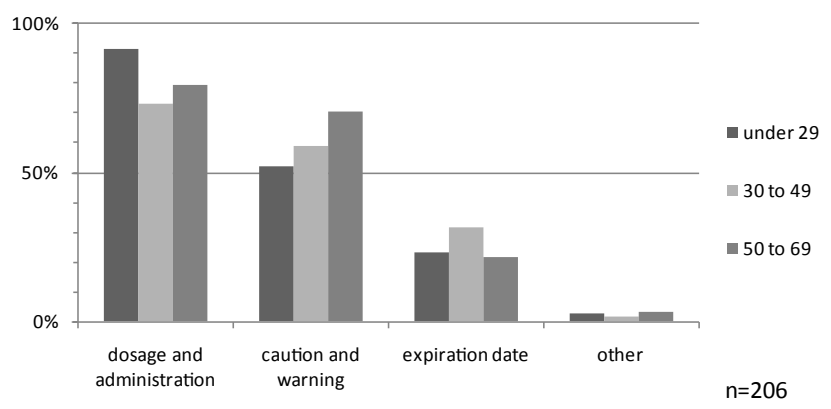

Figure 6: Ensured items for using ОTC drugs. (Comparison of age).

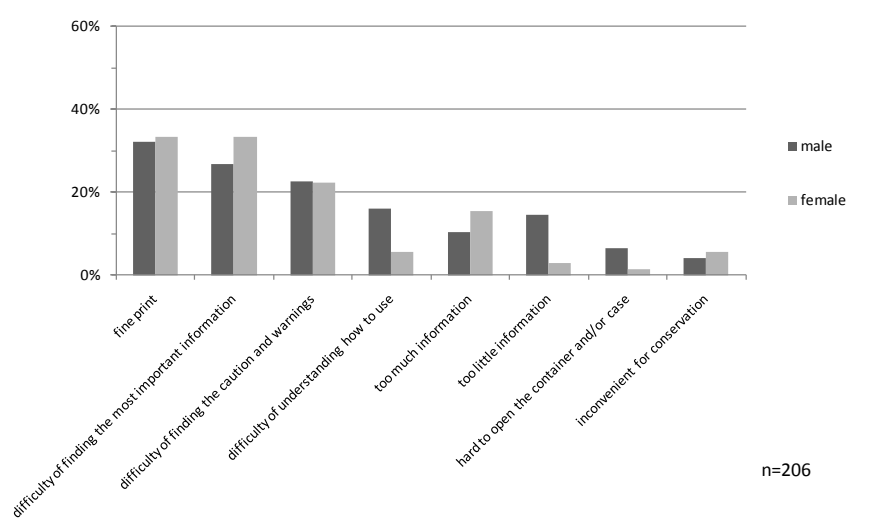

Figure 7: Problematic points on packaging of OTC drugs. (Comparison of sex).

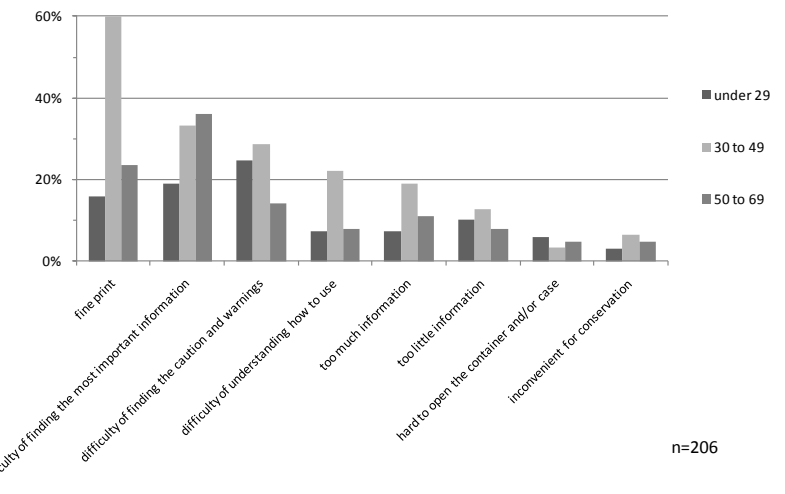

Figure 8: Problematic points on packaging of OTC drugs. (Comparison of age). 
information is also rated as inconvenient, male; $26 \%$ and female; $33 \%$. Male users think that there is difficulty in understanding how to use medicine (16\%) and too little information (14\%). On the other hand, female users think information is excessive (15\%); this result is opposite to that of male. As for other items, less than $10 \%$ of all users think there are problems with the instructions.

\section{Discussion}

Table 1 showed the distribution of age and sex of people who answered the questionnaire. We randomly distributed the questionnaire; and responding patients are distributed in every age group. So the analysis of results may reflect public opinion and needs in Japanese society. As for the criterion an item of choice of OTC drugs when they purchase drugs, the effectiveness is the higher priority in every age group and either sex. About half of users place importance on price, considering access of medication; price could be the important item for wide use of OTC drugs. Among other items of Figure 1, female users look upon recommendation from family, acquaintance and shop staff more often than males.

This suggests that female users trust the actual results of others more than TV commercials or brand name. Pharmacy staff should recognize this tendency in female patients. From Figure 2 30's and 40's are very conscious about brand name compared with other generations. These patients have responsibility for their families, and desire reliable and cost-effective OTC drugs when they make a purchase.

The most common item of instruction when patient use OTC drugs are instruction of the box. (Figures 3,4$),(60 \%$ or more.) This is similar to a previous study [6,7]. However, it also suggests another $40 \%$ of users miss the instruction on box. Furthermore, less than $20 \%$ of users of every generation give attention to instruction of the container (bottle), and less than $30 \%$ of users pay attention to package insert. In a previous study, less than $20 \%$ of users were satisfied with instruction of OTC drugs, and about $60 \%$ prefer to consult a some professional [7-9]. The findings support the need understandable instructions and appropriate professional consultation in community pharmacy.

Users confirming items when they take OTC drugs are shown in Figures 5, 6. Reviewing the appropriate dosage and administration schedule are the most common in every generation and distinction of sex. However, since attention for caution and warning are being confirmed $52 \%$ to $70 \%$ of all users, it means that at least $30 \%$ of users miss cautions and side-effect information. The pharmacy staff could emphasize this information at the time of purchase.

Figures 7, 8 show problematic points on packaging of OTC drugs. Compare with prescription drug, once users purchase for OTC drugs, that is used with users own responsibility and there is few opportunity of checking their usage and keeping status. So we try to discover what item is inconvenience for users. Fine print is chased most inconvenience in both male; $32 \%$ and female; $33 \%$. Not only elderly users but more than $30 \%$ of over 30 's complain about it. It is related to the result of Figures 3, 4 users tend to see the information of box, letter printed in there could be the most priority item of understandable expression. And difficulty of finding the most important information is also the item of inconvenience, male; $26 \%$ and female; $33 \%$. This result is serious message from users, even within the rule of instruction of OTC drugs packaging in Japan, we should device a clear instruction of essentially important information in the box [10]. There is the difference of impression from quantity of information between male and female. Thinking that same information gives different impression, pharmacists could behave simple explanation for female for example, it may become a strategy for selling OTC drugs for male and female.

\section{Conclusion}

From this study, we recognize that information of outer box is the most common information source for all users. In addition, users want simple instruction of the most important information about OTC drugs on the box.

- OTC manufactures should recognize this important tendency.

- Although package inserts contain detailed information, few patients review the information.

- Warning \& cautions are easily overlooked by consumers. A uniform method to emphasize there is recommended.

After the revised Pharmaceutical Affairs Act has been enforced, the demand of OTC drugs has increased with various places including supermarket, convenience store, and station shops in Japan. Considering such changing situation, the role of packages of OTC drugs is the key for safer self-medication in Japan and the concept could be universal in the world.

\section{References}

1. Ministry of Health, Labor and Welfare (2009) Vital Statistics of JAPAN 2007 Health and Welfare Statistics Association, Tokyo.

2. WHO (2000) Guideline for the regulatory assessment of medication products for use in self-medication. WHO Drug Information 14: 18-26.

3. Brass EP (2004) Consumer behavior in the setting of over-the-counter stain availability; lessons from the consumer use study of OTC mevacor. Am J Cardiol 94: 22F-29F.

4. Kishimoto K, Yoshida T, Fukushima N (2009) The factors related to purchasing Over- the-counter Medications Online. Yakugaku Zasshi 129: 1127-1136.

5. Simoens S, Lobeau M, Verbeke K, van Aerschot A (2009) Patient experiences of over-the-counter medicine purchases in Flemish community pharmacies. Pharm World Sci 31: 450-457.

6. Jhon DN, Krska J, Hansford D (2003) Are customers requesting medicines by name less likely to be advised or referred? Provision of over-the-counter $\mathrm{H} 2$ recepter antagonists and alginate products from pharmacies. Int J Pharm Pract 11: 33-39.

7. Narui K, Suetsugu D, Watanabe K (2010) Survey of Consumer Viw on Non-prescription Drug and Self-medication before Enactment of Revised Pharmaceutical Affaires Law in 2009. Jpn J Pharm Health Care Sci 36: 240251.

8. Watson MC, Hart J, Johnston M, Bond CM (2008) Exploring the supply of nonprescription medicines from community pharmacies in Scotland. Pharm World Sci 30: 526-535.

9. Ministry of internal Affairs and Communications (2007) Communication Usage Trend Survey in 2007 (at Households). June 2009 Pharmaceutical Administration and Regulation in Japan, Japan Pharmaceutical Manufacturers Association.

10. Daisuke Matsuo (2009) Effect of amendment to Japan's pharmaceutical affairs low. Nomura Research Institute Papers No149. 